Pesq. Vet. Bras. 29(5):387-394, maio 2009

\title{
Compactação primária do abomaso em 14 bovinos no Estado de Pernambuco ${ }^{1}$
}

\author{
Antônio Carlos Lopes Câmara ${ }^{2 *}$, José Augusto Bastos Afonso³, Nivaldo de \\ Azevêdo Costa $^{3}$, Carla Lopes de Mendonça ${ }^{3}$ e Maria Isabel de Souza ${ }^{3}$
}

\begin{abstract}
Câmara A.C.L., Afonso J.A.B., Costa N.A., Mendonça C.L. \& Souza M.I. 2009. [Primary abomasal impaction in 14 cattle from Pernambuco State, northeastern Brazil.] Compactação primária do abomaso em 14 bovinos no Estado de Pernambuco. Pesquisa Veterinária Brasileira 29(5):387-394. Clínica de Bovinos, Campus Garanhuns, Universidade Federal Rural de Pernambuco, Av. Bom Pastor s/n, Cx. Postal 152, Mundaú, Garanhuns, PE 55292-901, Brazil. E-mail: aclcamara@yahoo.com.br

Despite the frequent use of dry and fibrous roughage for feeding cows in many regions, especially during the dry season, impaction of the abomasum has been poorly reported in Brazil, probably because the condition is misdiagnosed by practitioners. The present paper aimed to accomplish a retrospective study on primary abomasal impaction in 14 cattle from Pernambuco State, northeastern Brazil. Eight moderate cases, without severe abdominal distention and with no rumen compaction, were treated conservatively, and four severe cases, with severe abdominal distention and rumen compaction, were treated surgically. One bull was slaughtered and one cow died without treatment. The greater number of abomasal impaction cases was in Holstein cows with six cases (42.9\%), followed by crossbred cattle with five cases (35.8\%), and the breeds Brown-Swiss, Nelore and Marchigiana, each with one case (21.3\%). The food composition was characterized by low quality fibers and varied greatly among cases. Most frequent clinical signs were apathy, dehydration, hypomotility and ruminal bloat, intestinal hypomotility and scanty or absent feces with mucus. The hematological findings revealed leukocytosis with neutrophilia and hyperfibrinogenemia in most cases. Ruminal fluid analysis showed compromised flora and fauna dynamics and increased chlorine ion concentration. Clinical $(4 / 8)$ and chirurgical (2/4) recovery rate achieved $50 \%$. The clinical and chirurgical methods remain as viable options for the treatment of light and severe impaction, but the prognosis is always reserved especially when associated to late pregnancy.
\end{abstract}

INDEX TERMS: Abomasum, cattle, impaction, vagal indigestion.

RESUMO.- Apesar de forragens grosseiras e secas serem empregadas comumente na alimentação de vacas em várias regiões, especialmente durante o período seco, a compactação primária do abomaso tem sido pouco relatada no Brasil, provavelmente pela dificuldade de diagnóstico dos

\footnotetext{
${ }^{1}$ Recebido em 8 de novembro de 2008.

Aceito para publicação em 17 de dezembro de 2008.

2 Hospital Escola de Grandes Animais da Granja do Torto, Faculdade de Agronomia e Medicina Veterinária, Universidade de Brasília. Galpão 4, Granja do Torto, Brasília, DF 70636-200, Brasil. *Autor para correspondência: aclcamara@yahoo.com.br

${ }^{3}$ Clínica de Bovinos, Campus Garanhuns, Universidade Federal Rural de Pernambuco, Av. Bom Pastor s/n, Bairro Mundaú, Caixa Postal 152, Garanhuns, PE 55292-901, Brasil.
}

veterinários de campo. Este trabalho objetivou realizar um estudo retrospectivo sobre a compactação primária do abomaso em 14 bovinos no Estado de Pernambuco. Oito casos considerados moderados, sem grave distensão abdominal e sem compactação do rúmen, foram tratados conservativamente e quatro casos graves, com severa distensão abdominal e compactação do rúmen, foram tratados cirurgicamente. Um touro foi encaminhado para abate e uma vaca morreu antes de receber qualquer tratamento. O maior número de casos de compactação do abomaso ocorreu em bovinos da raça Holandesa com seis casos $(42,9 \%)$, seguido por animais mestiços com cinco casos $(35,8 \%)$ e as raças Pardo-Suiça, Nelore e Marchigiana com um caso cada $(21,3 \%)$. A composição da alimentação ofe- 
recida caracterizou-se por conter fibra de baixa qualidade e variou bastante dentre os casos. Os sinais clínicos mais frequentes foram comportamento apático, desidratação, timpanismo ruminal associado à hipomotilidade, distensão abdominal, hipomotilidade intestinal e fezes escassas ou ausentes com presença de muco. Os achados hematológicos revelaram, na maioria dos casos, leucocitose por neutrofilia e hiperfibrinogenemia. $\mathrm{Na}$ análise do fluido ruminal havia comprometimento da dinâmica da flora e fauna microbiana, e elevação no teor de cloreto. O índice de recuperação clínica (4/8) e cirúrgica (2/4) observado neste estudo foi de $50 \%$. As condutas clínica e cirúrgica permanecem como opções viáveis para o tratamento das compactações leves e severas, entretanto o prognóstico é considerado reservado, principalmente quando associado à gestação avançada.

TERMOS DE INDEXAÇÃO: Compactação, abomaso, indigestão vagal, bovinos.

\section{INTRODUÇÃO}

Em bovinos de corte e leite, a função fisiológica do abomaso é fundamental para a saúde e o sucesso produtivo. A alteração funcional deste órgão é a razão mais habitual para cirurgia abdominal em bovinos leiteiros adultos e, com menor frequência, em bezerros, touros e bovinos de corte (Trent 2004).

As doenças do abomaso mais frequentes relatadas em bovinos são: o deslocamento do abomaso à esquerda, o deslocamento do abomaso à direita seguida ou não pelo vólvulo abomasal, as úlceras, a compactação associada com indigestão vagal e a compactação nutricional (Radostitis et al. 2007). A compactação do abomaso é definida como o acúmulo de ingesta dentro do órgão com falha no transporte aboral (Hoffsis \& McGuirk 1993, Saint Jean \& Anderson 1999, Guard 2006), sendo considerada uma causa frequente de indigestão vagal do tipo III (estenose funcional posterior) em bovinos (Moscardini \& Borges 2007).

A compactação do abomaso de origem primária pode ser causada pela ingestão de grande quantidade de forragem de baixa qualidade, associada ou não a restrição hídrica (Blikslager et al. 1993, Moscardini \& Borges, 2007). A compactação de abomaso devido à ingestão excessiva de areia ou cascalho e utilização de alimentos não-usuais, como cascas de amêndoas, também já foram relatadas (Purohit et al. 1987, Mitchell 1991, Cebra et al. 1996, Melendez et al. 2007). No Brasil, a ingestão de forrageiras trituradas ricas em lignina, com fibras curtas, e a ingestão de cama de frango com palha de arroz são as principais causas da enfermidade (Borges et al. 2007, Moscardini \& Borges 2007).

As causas secundárias incluem distúrbios de escoamento pilórico devido à lesões nos ramos ventrais do nervo vago, dano vascular ou neurogênico secundário a vólvulo abomasal, além das obstruções intraluminais, murais e extraluminais (Blikslager et al. 1993, Trent 2004, Guard 2006, Fubini \& Divers 2008). As causas mais comuns de obstrução intraluminal do piloro são por corpos estranhos, como fitobezoários, tricobezoários, placenta e sacos plásticos (Blikslager et al. 1993, Coutinho et al. 2002, Trent 2004, Dirksen 2005, Afonso et al. 2008). Qualquer massa extraluminal adjacente ao antro pilórico ou duodeno proximal que possa comprimir o lúmen pode ocasionar a obstrução total ou parcial do escoamento do conteúdo do abomaso, sendo considerados os fatores mais comuns os abscessos e a necrose do tecido gorduroso do omento (Trent 1990, 2004). As causas murais consistem de fibroses e abscessos resultantes de úlceras perfuradas ou reticuloperitonite traumática e tumores, dos quais o mais comum é o linfossarcoma seguido do adenocarcinoma (Blikslager et al. 1993, Trent 2004). Outras causas citadas abrangem a colocação imprópria de suturas às cegas (método "toggle"), omentopexia ou piloropexia e compressão pilórica pelo útero gravídico, principalmente no trimestre final de gestação (Kelton \& Fubini 1989, Saint Jean \& Anderson 1999, Whitlock 1999).

No Brasil, apesar de forragens grosseiras e secas, ricas em lignina, serem empregadas comumente na alimentação de vacas em várias regiões, especialmente durante o período seco, a compactação de abomaso tem sido pouco diagnosticada. Entretanto, pela dificuldade do diagnóstico, é possível que muitos casos possam passar despercebidos pelos médicos veterinários que desenvolvem suas atividades em diferentes propriedades rurais, constituindo apenas um achado incidental na necropsia ou em matadouros (Borges et al. 2007). O presente trabalho teve como objetivo realizar um estudo retrospectivo sobre os achados clínicos e laboratoriais da compactação primária do abomaso em 14 bovinos no Estado de Pernambuco, bem como determinar a eficiência dos tratamentos utilizados.

\section{MATERIAL E MÉTODOS}

O estudo sobre a ocorrência da compactação do abomaso em Pernambuco foi realizado com as informações obtidas a partir das fichas de acompanhamento clínico de 14 bovinos adultos (11 fêmeas e três machos), oriundos de municípios pernambucanos e atendidos na Clínica de Bovinos, Campus Garanhuns, Universidade Federal Rural de Pernambuco, de janeiro de 2000 a janeiro de 2008 .

Todos os animais foram examinados clinicamente seguindo as recomendações de Dirksen et al. (1993), enquanto nas fêmeas realizou-se, também, o diagnóstico de gestação por meio de palpação retal. Foram coletadas amostras sanguíneas de seis animais em tubo a vácuo com anticoagulante EDTA (10\%), para realização de hemograma segundo Jain (1993). Doze amostras de fluido ruminal foram analisadas de acordo com Dirksen et al. (1993). Em sete amostras foi realizada a dosagem do teor de cloretos, empregando-se kit comercial (Labtest Diagnóstica), sendo a leitura efetuada em analisador bioquímico semi-automático (Labquest). Não se tinha registro do hemograma, análise do fluido ruminal e dosagem do teor de cloretos em oito, dois e sete animais, respectivamente.

Após o diagnóstico três alternativas foram consideradas: 1) indicar os animais para abate por opção do proprietário após avaliação da relação custo-benefício; 2) submetê-los ao tratamento conservativo quando a condição clínica não representava 
risco de morte para o animal e não havia compactação de rúmen concomitante, sendo o quadro clínico considerado moderado; e 3) submetê-los a tratamento cirúrgico nos casos em que havia distensão acentuada do abdômen associada à compactação de rúmen, sendo considerados como graves.

Nos casos diagnosticados como moderados foram realizadas a fluidoterapia para correção do desequilíbrio hídricoeletrolítico, transfaunação com fluido ruminal de animais sadios e administração diária oral de suco de mandacaru (Cereus jamacaru), que tem função laxativa e é preparado retirando-se o caule e descascando-o para retirada dos espinhos e triturando-o com água em liquidificador (Afonso \& Borges 2007). Nos casos graves realizou-se a laparotomia pelo flanco esquerdo seguida de rumenotomia (Ducharme \& Fubini 2004), com subsequente retirada da ingesta, infusão de suco de mandacaru através do orifício retículo-omasal seguida de transfaunação. Os animais permaneceram internados para acompanhamento pós-operatório com instituição de terapia composta por antibió- ticos (oxitetraciclina LA; 20mg/kg; via intramuscular; 72/72 horas; três aplicações) e antiinflamatórios não-esteroidais (fenilbutazona, $4 \mathrm{mg} / \mathrm{kg}$, via intra-muscular, 24/24 horas, duas aplicações), além de terapia de suporte com fluídos administrados por via oral (suco de mandacaru pela manhã e fluido ruminal à tarde obtido de animais saudáveis, em torno de 10 litros/vez). Foi ainda realizada a fluidoterapia endovenosa e aplicações de soluções de cálcio diariamente. Durante o tempo de tratamento a alimentação era à base de forragem de qualidade (capim elefante cortado em fibras de $10 \mathrm{~cm}$ de comprimento e Tifton) e água ad libitum. Os animais eram, também, estimulados ao exercício. Nos casos em que não foi possível fazer o diagnóstico pelo exame clínico e resultado das análises laboratoriais foi feita laparotomia pelo flanco direito para confirmação da compactação de abomaso e utilizada a mesma terapia para os casos considerados graves, mas estes animais foram incluídos no grupo do tratamento clínico.Todos os bovinos que morreram durante o internamento foram necropsiados.

Quadro 1. Dados epidemiológicos, evolução clínica, conduta terapêutica e resolução clínica em 14 bovinos com compactação primária do abomaso no Estado de Pernambuco

\begin{tabular}{|c|c|c|c|c|c|c|c|c|c|c|c|}
\hline Bovino & o Raça & Idade $\varsigma$ & Sexc & Prenhez & $\begin{array}{l}\text { Sistema de } \\
\text { criação }\end{array}$ & Alimentação & $\begin{array}{c}\text { Mês/es- } \\
\text { tação da } \\
\text { ocorrência }\end{array}$ & $\begin{array}{l}\text { Evolução } \\
\text { clínica }^{a}\end{array}$ & $\begin{array}{l}\text { Conduta } \\
\text { terapêutica }\end{array}$ & Município $\mathrm{R}$ & Resolução \\
\hline 1 & Holandesa & 5 anos & $\mathrm{F}^{\mathrm{b}}$ & 6 meses & Semi-intensivo & $\begin{array}{l}\text { Silagem de capim ele- } \\
\text { fante, palma forrageira e } \\
\text { concentrado }\end{array}$ & $11 /$ seca & 3 dias & Clínica & Bom Conselho & Alta \\
\hline 2 & Holandesa & 4 anos & $\mathrm{F}$ & Não & Semi-intensivo & $\begin{array}{l}\text { Capim elefante triturado } \\
\text { e casca de mandioca }\end{array}$ & $01 /$ seca & 3 dias & Clínica & Caruaru & Óbito \\
\hline $4 \mathrm{~F}$ & Pardo-Suiça & 6 anos & $\mathrm{F}$ & 4 meses & Semi-intensivo & $\begin{array}{l}\text { Palma forrageira, casca } \\
\text { de mandioca e concen- } \\
\text { trado }\end{array}$ & $11 /$ seca & 5 dias & Clínica & Pedra & Óbito \\
\hline 5 & Holandesa & 1,5 anos & $M$ & - & Semi-intensivo & $\begin{array}{l}\text { Capim elefante triturado } \\
\text { e palha de milho. }\end{array}$ & 09 / seca & 4 dias & Clínica & Paranatama & Alta \\
\hline 6 & Mestiça & 6 anos & $\mathrm{F}$ & 6 meses & Intensivo & $\begin{array}{l}\text { Capim elefante tritura- } \\
\text { do, casca de mandioca, } \\
\text { bagaço de cana e con- } \\
\text { centrado }\end{array}$ & 03 / chuva & 3 dias & Clínica & Saloá & Óbito \\
\hline 8 & Mestiça & 3 anos & $\mathrm{F}$ & Não & Semi-intensivo & $\begin{array}{l}\text { Capim elefante triturado } \\
\text { e cama de frango. }\end{array}$ & 02 / seca & 3 dias & Clínica & São João & Alta \\
\hline 9 & Holandesa & 3 anos & $\mathrm{F}$ & $>8$ meses & Intensivo & $\begin{array}{l}\text { Silagem de capim ele- } \\
\text { fante, casca de mandi- } \\
\text { oca, palma forrageira e } \\
\text { concentrado }\end{array}$ & 01 / seca & 8 dias & - & Pedra & Óbito \\
\hline 10 & Mestiça & $>10$ anos & $F$ & Não & Semi-intensivo & $\begin{array}{l}\text { Capim elefante tritura- } \\
\text { do, casca de mandioca } \\
\text { e concentrado }\end{array}$ & $01 /$ seca & 3 dias & Cirúrgica & Caetés & Alta \\
\hline 11 & Nelore & 2 anos & M & - & Intensivo & $\begin{array}{l}\text { Capim elefante triturado } \\
\text { e concentrado à vontade }\end{array}$ & 08 / chuva & 12 dias & Cirúrgica & Imbimirim & Alta \\
\hline 12 & Holandesa & 6 anos & $\mathrm{F}$ & $>8$ meses & Semi-intensivo & $\begin{array}{l}\text { Capim elefante tritura- } \\
\text { do, casca de mandioca } \\
\text { e concentrado }\end{array}$ & 07 / chuva & 4 dias & Cirúrgica & Caruaru & Óbito \\
\hline
\end{tabular}

a Dias após o início dos sinais clínicos observados pelos proprietários ou tratadores.

b $\mathrm{F}=$ fêmea, $\mathrm{M}$ = macho. 


\section{RESULTADOS}

Os dados epidemiológicos, evolução clínica, conduta terapêutica e resolução clínica dos casos estão resumidos no Quadro 1. A maioria dos bovinos era criada em sistema semi-intensivo, com livre acesso a alimentos volumosos no pasto como capim Buffel (Cenchrus ciliaris), capim elefante (Pennisetum purpureum), grama estrela (Cynodon nlemfuensis) e/ou pastagem nativa. Os animais confinados recebiam toda a alimentação no cocho, como também ocorria na suplementação oferecida aos bovinos do sistema de criação semi-intensivo, que consistia da mistura de diversos alimentos, dentre eles: capim elefante triturado $(78,6 \%)$, concentrado comercial $(64,3 \%)$, casca de mandioca $(50 \%)$, cama de frango $(28,6 \%)$, palma forrageira (Opuntia fícus indica) $(21,4 \%)$, silagem de capim elefante $(14,3 \%)$, palha de milho $(14,3 \%)$ e bagaço de cana $(7,1 \%)$ (Quadro 1).

Oito casos foram considerados moderados devido a ausência de distensão abdominal grave e sem compactação do rúmen, sendo tratados conservativamente, enquanto quatro casos com severa distensão abdominal associada a compactação do rúmen, foram considerados graves e tratados cirurgicamente. Um dos bovinos macho (Caso 13) foi encaminhado para abate por opção do proprietário após avaliação da relação custo-benefício. Uma das vacas (Caso 9) deitou-se durante o transporte para o centro cirúrgico e morreu depois de duas horas, sem receber nenhum tipo de tratamento. Em dois casos (Casos 4 e 6) foi utilizada a laparotomia exploratória pelo flanco direito para confirmação do diagnóstico de compactação de abomaso.

Os casos de compactação apresentaram a seguinte distribuição durante as estações no período estudado: 10 casos $(71,4 \%)$ na estação seca (meados de setembro a fevereiro) e quatro casos $(28,6 \%)$ na estação chuvosa (março a agosto).

Os principais sinais clínicos observados e relatados pelos proprietários eram diminuição gradativa ou abrupta do apetite, queda da produção leiteira, timpanismo leve a severo e fezes escassas ou ausentes. A evolução clínica variou entre 2-12 dias. Os resultados dos exames clínicos são apresentados no Quadro 2. Os sinais clínicos mais observados eram: comportamento apático, com diferentes níveis de indiferença aos estímulos externos; graus variados de desidratação; dispnéia inspiratória associada à taquipnéia devido à compressão diafragmática; timpanismo ruminal leve a severo com motilidade ausente ou diminuída; distensão abdominal uni ou bilateral; hipomotilidade intestinal; e, fezes escassas ou ausentes com presença de muco. O achado clínico de maior importância no diagnóstico da compactação de abomaso foi a presença de estrutura compactada na localização do órgão durante a palpação abdominal ventral profunda em três casos. O diagnóstico de gestação revelou que das onze fêmeas examinadas, sete $(63,6 \%)$ apresentavamse prenhes com período gestacional no quarto (1/7), sexto (2/7) e acima do oitavo mês (4/7). Em nenhum dos ani-

\section{Quadro 2. Resultados do exame clínico em 14 bovinos com compactação de abomaso no Estado de Pernambuco}

\begin{tabular}{|c|c|c|}
\hline Característica & Achado Clínico & $\begin{array}{l}\text { Número } \\
\text { de animais }\end{array}$ \\
\hline \multirow[t]{3}{*}{ Comportamento } & Ativo & 4 \\
\hline & Calmo & 2 \\
\hline & Apático & 8 \\
\hline \multirow[t]{4}{*}{ Escore corporal } & V & 1 \\
\hline & IV & 1 \\
\hline & III & 9 \\
\hline & II & 3 \\
\hline \multirow[t]{4}{*}{ Grau de desidratação } & Grave & 7 \\
\hline & Moderado & 3 \\
\hline & Leve & 3 \\
\hline & Sem alteração & 1 \\
\hline \multirow[t]{2}{*}{ Enoftalmia } & Presente & 3 \\
\hline & Sem alteração & 11 \\
\hline \multirow[t]{2}{*}{ Apetite } & Sem alteração & 5 \\
\hline & Ausente & 9 \\
\hline \multirow[t]{2}{*}{ Falso vômito } & Presente & 1 \\
\hline & Ausente & 13 \\
\hline \multirow[t]{3}{*}{ Temperatura retal } & Normal $\left(38,0-39,0^{\circ} \mathrm{C}\right)$ & 8 \\
\hline & Baixa $\left(<38,0^{\circ} \mathrm{C}\right)$ & 1 \\
\hline & Aumentada $\left(>39,0^{\circ} \mathrm{C}\right)$ & 5 \\
\hline \multirow{3}{*}{$\begin{array}{l}\text { Frequência cardíaca } \\
\text { (batimentos/minuto) }\end{array}$} & Normal $(60-80)$ & 8 \\
\hline & Aumento moderado $(81-100)$ & 3 \\
\hline & Aumento severo $(>100)$ & 3 \\
\hline \multirow{3}{*}{$\begin{array}{l}\text { Frequência respiratória } \\
\text { (movimentos/minuto) }\end{array}$} & Normal (24-36) & 8 \\
\hline & Baixa $(\leq 20)$ & 2 \\
\hline & Aumentada (>40) & 4 \\
\hline \multirow[t]{3}{*}{ Motilidade ruminal } & Aumentada & 3 \\
\hline & Reduzida ou ausente & 10 \\
\hline & Normal & 1 \\
\hline \multirow[t]{3}{*}{ Timpanismo ruminal } & Leve & 5 \\
\hline & Severo & 6 \\
\hline & Ausente & 3 \\
\hline Motilidade intestinal & Reduzida & 14 \\
\hline \multirow{5}{*}{ Contorno abdominal } & Sem alteração & 3 \\
\hline & Piriforme & 2 \\
\hline & Abaulamento bilateral & 4 \\
\hline & Abaulamento unilateral esquerdo & 2 \\
\hline & Abaulamento unilateral direito & 3 \\
\hline \multirow[t]{2}{*}{ Tensão abdominal ${ }^{a}$} & Fisiológica & 3 \\
\hline & Aumentada & 11 \\
\hline \multirow{2}{*}{$\begin{array}{l}\text { Palpação abdominal } \\
\text { ventral profunda }\end{array}$} & Presença de estrutura compactada & 3 \\
\hline & Sem alteração & 11 \\
\hline \multirow[t]{2}{*}{ Provas de dor } & Positiva (alguma prova) & 1 \\
\hline & Negativa & 13 \\
\hline \multirow[t]{3}{*}{ Palpação retal } & Sem anormalidades palpáveis & 3 \\
\hline & Rúmen compactado & 5 \\
\hline & Rúmen dilatado & 6 \\
\hline \multirow[t]{4}{*}{ Fezes } & Fisiológicas & 3 \\
\hline & Ressecadas & 1 \\
\hline & Escassas & 5 \\
\hline & Ausentes & 5 \\
\hline \multirow[t]{2}{*}{ Misturas anormais nas fezes } & Nenhuma & 8 \\
\hline & Muco & 6 \\
\hline
\end{tabular}

a Parâmetro influenciado nos seis casos em vacas no trimestre final de gestação.

mais foi possível palpar o abomaso ou omaso compactados através do exame retal.

Os achados hematológicos, da proteína plasmática total e do fibrinogênio plasmático são encontrados no Quadro 3. As alterações mais comuns nos seis animais 


\section{Quadro 3. Valores hematológicos, proteína plasmática total e fibrinogênio plasmático em seis bovinos diagnosticados com compactação primária de abomaso no Estado de Pernambuco}

\begin{tabular}{|c|c|c|c|c|c|c|c|c|}
\hline Parâmetro & Caso 1 & Caso 4 & Caso 6 & Caso 9 & Caso 11 & Caso 12 & $\mathrm{X} \pm \mathrm{Sd}$ & $\begin{array}{l}\text { Valores de } \\
\text { referência }\end{array}$ \\
\hline Hematócrito (\%) & 33 & 48 & 37 & 31 & 35 & 34 & $35,85 \pm 5,52$ & $24-46$ \\
\hline Hemácias (x 106/uL) & 7,1 & 10,94 & 8,85 & 7,09 & 7,97 & 5,18 & $7,74 \pm 1,77$ & $5-10$ \\
\hline Hemoglobina (g/dL) & 10,9 & 15,91 & 11,75 & 10,55 & 12,27 & - & $12,04 \pm 1,91$ & $8-15$ \\
\hline $\operatorname{VCM}^{a}(f L)$ & 46,50 & 43,88 & 41,80 & 43,72 & 43,91 & 65,53 & $47,40 \pm 8,15$ & $40-60$ \\
\hline $\mathrm{CHCM}^{\mathrm{b}}(\%)$ & 33 & 33,15 & 31,75 & 34,06 & 35,05 & 29,38 & $32,77 \pm 1,80$ & $30-36$ \\
\hline $\mathrm{PPT}^{\mathrm{C}}(\mathrm{g} / \mathrm{dL})$ & 9,6 & 9,9 & 8,3 & 7,0 & 8,0 & 9,8 & $8,88 \pm 1,07$ & $7,0-8,5$ \\
\hline $\mathrm{FP}^{\mathrm{d}}(\mathrm{mg} / \mathrm{dL})$ & - & 1100 & 800 & 900 & 800 & 1300 & $980 \pm 193$ & $300-700$ \\
\hline Leucócitos totais $(/ \mu \mathrm{L})$ & 9250 & 9950 & 18150 & 15650 & 10000 & 16024 & $13457 \pm 4799$ & $4000-12000$ \\
\hline Neutrófilos (/ $\mu \mathrm{L})$ & 4440 & 6667 & 6353 & 7669 & 3700 & 5488 & $5536 \pm 1346$ & $600-4000$ \\
\hline Linfócitos $(/ \mu \mathrm{L})$ & 3885 & 2686 & 11253 & 7669 & 5100 & 16024 & $7214 \pm 4627$ & $2500-7500$ \\
\hline 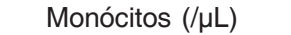 & 463 & 498 & - & - & 900 & 439 & $552 \pm 188$ & $25-840$ \\
\hline Eosinófilos $(/ \mu \mathrm{L})$ & 462 & - & - & 157 & 300 & - & $345 \pm 125$ & $0-2400$ \\
\hline 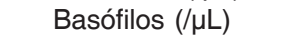 & - & - & 73 & 157 & - & - & $115 \pm 42$ & $0-200$ \\
\hline Bastonetes $/ \mu \mathrm{L}$ ) & - & 99 & 545 & - & - & - & $521 \pm 23$ & - \\
\hline
\end{tabular}

$\bar{a}$ Volume corpuscular médio, ${ }^{b}$ Concentração de hemoglobina corpuscular média, ${ }^{c}$ proteína plasmática total,

d fibrinogênio plasmático, ${ }^{e}$ Kramer (2000).

analisados consistiram de leucocitose por neutrofilia e hiperfibrinogenemia. Os demais parâmetros encontravamse dentro dos limites fisiológicos para a espécie (Kramer 2000).

Os resultados da análise do fluido ruminal e dosagem do teor de cloretos são apresentados no Quadro 4. As amostras analisadas apresentaram coloração que variou do castanho esverdeado (7/12), verde-oliva (2/12), castanho (2/12) a castanho-amarelada (1/12). O odor alterado (odor insípido indiferente) foi observado em três casos. A consistência do fluído ruminal variou de aquosa (1/12) e levemente viscosa (9/12) a viscosa (2/12), enquanto os valores de $\mathrm{pH}$ variaram entre $7,0(6 / 12)$ e $8,0(6 / 12)$. 0 teor de cloretos no fluido ruminal apresentava-se elevado ( $>30 \mathrm{mEq} / \mathrm{L}$ ) em seis de sete casos $(85,7 \%)$, sendo o índice médio de $66,08 \mathrm{mEq} / \mathrm{L}$.
O índice de recuperação total alcançou 50\% (6/12). Ambos os tratamentos, clínico (4/8) e cirúrgico (2/4), apresentaram índice de sobrevivência de 50\%.

Os sete animais que foram submetidos à necropsia apresentaram alterações semelhantes que consistiram de abomaso aumentado de volume e com conteúdo alimentar bem compactado, associado à compactação de omaso e rúmen (4/7). Três casos (Casos 6, 7 e 14) apresentaram ruptura no abomaso que variou de 5 a $15 \mathrm{~cm}$ com bordos edemaciados, avermelhados e com presença de filamentos de coágulos, caracterizando a ruptura in vivo, além do quadro macroscópico de peritonite fibrino-purulenta difusa. Intestinos com muco e pouco ou nenhum conteúdo foi um achado comum. Verificou-se ainda que das sete vacas prenhes, seis morreram durante o internamento hospitalar, constatando-se a presença de

Quadro 4. Análise do fluido ruminal $(n=12)$ e dosagem do teor de cloretos $(n=7)$ em bovinos com compactação primária do abomaso no Estado de Pernambuco

\begin{tabular}{|c|c|c|c|c|c|c|c|c|}
\hline $\begin{array}{l}\text { Parâmetro/ } \\
\text { Caso }\end{array}$ & Cor & Odor & Consistência & $\mathrm{pH}$ (grau) & $\begin{array}{l}\text { Protozoários } \\
\text { vivos }(\%)\end{array}$ & $\begin{array}{l}\text { PRAMa } \\
\text { (minutos) }\end{array}$ & $\begin{array}{c}\text { TAS }^{\mathrm{b}} \\
\text { (minutos) }\end{array}$ & $\begin{array}{l}\text { Teor de } \\
\text { cloretos } \\
(\mathrm{mEq} / \mathrm{L})\end{array}$ \\
\hline 1 & Castanho & Aromático & Levemente viscosa & 8 & 30 & 12 & $\mathrm{QI}^{\mathrm{C}}$ & 28,7 \\
\hline 3 & Castanho-esverdeado & Aromático & Levemente viscosa & 7 & 5 & 7 & 8 & - \\
\hline 4 & Castanho-esverdeado & Alterado & Levemente viscosa & 7 & 5 & $>15$ & 11 & 103,45 \\
\hline 6 & Verde-oliva & Aromático & Levemente viscosa & 8 & 5 & 7 & 20 & 45,98 \\
\hline 9 & Verde-oliva & Aromático & Aquosa & 7 & 20 & 10 & 1 & 113,8 \\
\hline 10 & Castanho-esverdeado & Aromático & Viscosa & 8 & 40 & 13 & $\mathrm{QI}^{\mathrm{C}}$ & - \\
\hline 11 & Castanho-esverdeado & Aromático & Levemente viscosa & 7 & 10 & 12 & $\mathrm{QI}^{\mathrm{C}}$ & 36,75 \\
\hline 12 & Castanho-esverdeado & Aromático & Viscosa & 7 & 10 & $>15$ & 3 & 96,85 \\
\hline 14 & Castanho-esverdeado & Alterado & Levemente viscosa & 7 & 10 & Ausente & 7 & - \\
\hline $\begin{array}{l}\mathrm{X} \pm \mathrm{Sd} \\
\text { Valores de } \\
\text { referência }\end{array}$ & Variados $^{\mathrm{e}}$ & Aromático & $\begin{array}{c}- \\
\text { Levemente viscosa }\end{array}$ & $\begin{array}{c}7,5 \pm 0,52 \\
5,5-7,4^{e}\end{array}$ & $\begin{array}{c}13,33 \pm 11,14 \\
90-100\end{array}$ & $\begin{array}{c}10,87 \pm 2,64 \\
3-6\end{array}$ & $\begin{array}{c}6,75 \pm 6,40 \\
4-8\end{array}$ & $\begin{array}{c}66,08 \pm 36,80 \\
<30\end{array}$ \\
\hline
\end{tabular}

a Prova de redução do azul de metileno, b Tempo de sedimentação e flotação, c Quantidade insuficiente, d Dirksen et al. (1993), e Parâmetro influenciado de acordo com a alimentação. 
feto grande ocupando grande porção da cavidade abdominal em quatro fêmeas (Casos 6, 9, 12 e 14), sendo diagnosticada a síndrome de indigestão vagal, particularmente, a do tipo IV (Whitlock, 1999). Um dos animais (Caso 7) pariu com auxílio obstétrico um bezerro macho durante o internamento e após cinco dias veio à óbito. Outra vaca (Caso 4) possuía feto de aproximadamente 4 meses, o qual não provocava compressão pilórica.

\section{DISCUSSÃO}

O maior número de casos de compactação do abomaso ocorreu em bovinos da raça Holandesa com seis casos $(42,9 \%)$, seguido por animais mestiços (Holandesa $\times$ Gir) com cinco casos $(35,8 \%)$ e as raças Pardo-Suiça, Nelore e Marchigiana com um caso cada (21,3\%) (Quadro 1). Este fato é justificado pela predominância de raças leiteiras no Agreste Meridional e Sertão de Pernambuco, uma vez que aproximadamente $70 \%$ do leite consumido no Estado são produzidos nesta região (CEASA-PE 2007). A menor incidência observada em raças de corte neste estudo $(14,2 \%)$ é decorrente da menor população de bovinos desta aptidão na região e corrobora os achados de Borges et al. (2007) em estudos realizados nos Estados de Goiás, Rio de Janeiro e Distrito Federal; enquanto que em alguns países de clima frio, principalmente durante os meses de inverno, a compactação primária do abomaso é mais frequente em bovinos de corte (Hoffsis \& McGuirk 1993, Trent 2004, Guard 2006).

A maior ocorrência deste distúrbio digestivo na estação seca decorre da escassez de forragem de qualidade nesta época do ano. Este fato associado ao deficiente manejo de pastagens em diversas propriedades propicia o surgimento da compactação primária do abomaso mesmo em animais confinados e durante a estação chuvosa (Casos 6 e 11), pois a doença pode desenvolver-se, muitas vezes, lentamente ao longo de um período de dias a semanas (Guard 2006, Melendez et al. 2007, Radostitis et al. 2007). Além disso, todos os animais são oriundos de propriedades localizadas no Agreste (13/14) e Sertão (1/14) Pernambucano, onde a distribuição das chuvas é, frequentemente, irregular e ocorrem períodos de estiagem mais prolongados.

O principal fator associado à ocorrência da compactação primária do abomaso foi a utilização de forragem de capim-elefante em estado avançado de maturidade e com grande concentração de lignina associado ao uso da picadeira que reduz muito o tamanho das partículas da forrageira (Borges et al. 2007). A forragem triturada é comumente misturada com grãos ou concentrados comerciais, mas costuma ter um nível insuficiente para atender as demandas energéticas. As partículas menores da forragem triturada ou da mistura forragem triturada/grãos podem levar a passagem mais rápida pelo retículo-rúmen e provocar a compactação de abomaso, omaso e rúmen (Borges et al. 2007, Radostitis et al. 2007). Fato também observado na ingestão, por algum tempo, de feno de má qualidade, palha, bagaço de cana e outras forragens se- cas com pouca digestibilidade (Afonso \& Borges 2007). Observou-se, ainda, o uso indiscriminado da cama de frango pelos produtores, que é proibido para alimentação de ruminantes e que foi considerado um dos fatores na etiologia da enfermidade em alguns dos casos, pois apresenta reduzido teor de nutrientes digestíveis totais, caracterizando-se como um alimento de baixa qualidade para ruminantes (Alves 1999). A palma forrageira (Opuntia ficus-indica) apresenta alta produção de matéria seca por unidade de área e é uma excelente fonte de energia, rica em carboidratos não-fibrosos e nutrientes digestíveis totais. Por outro lado, possui baixos teores de matéria seca ( $10 \%$ a $14 \%)$, proteína bruta ( $4 \%$ a $6 \%$ ) e fibra em detergente neutro $(26,8 \%)$. Estas características podem causar perda de peso, depressão na produção e no teor de gordura do leite, bem como distúrbios digestivos (diarréias e ruminação pobre) (Andrade et al. 2002), principalmente quando utilizada como alimento único ou associada a volumosos de baixa qualidade. Outro fato importante é o uso desta cactácea muito velha na alimentação, o conteúdo da fibra eleva-se e é considerado de péssima qualidade, aumentando o risco na formação de fitobezoários (Afonso et al. 2008).

Os sinais clínicos observados são semelhantes aos comentados na literatura (Braun et al. 1990, Mitchell 1991, Blikslager et al. 1993, Hoffsis \& McGuirk 1993, Simkins \& Nagele 1997, Saint Jean \& Anderson 1999, Dirksen 2005, Guard 2006, Moscardini \& Borges 2007, Borges et al. 2007, Radostitis et al. 2007, Fubini \& Divers 2008). O principal sinal clínico para confirmação do diagnóstico foi a presença de uma estrutura compactada no abdômen ventral direito na localização do abomaso durante a palpação abdominal profunda (Casos 3, 5 e 10), sendo tal achado evidenciando também em bovinos com compactação por areia, desde que a quantidade de geossedimento ultrapasse $5 \mathrm{~kg}$ (Dirksen et al. 1993). O diagnóstico pré-operatório de compactação do abomaso foi dificultado pela prenhez avançada em alguns casos limitando o exame da cavidade abdominal pelo reto, assim como observados em vacas prenhes com compactação de ceco (Desrochers \& Saint Jean 1995), todavia mesmo nas fêmeas vazias e nos machos não foi possível a palpação do abomaso ou omaso compactados.

A ocorrência deste tipo de distúrbio durante a gestação, principalmente na fase mais avançada, se deve a esta categoria de animais ser mais exigente quanto ao nível de proteínas digeríveis e quantidade de energia no alimento. Isto ocorre também no período pós-parto, quando as fêmeas tornam-se mais susceptíveis à doença, pelo fato de ingerirem maior quantidade de alimento, expondo-se ao maior risco do que as demais categorias (Hoffsis \& McGuirk 1993, Moscardini \& Borges 2007). Acreditase, ainda, que na gestação avançada, principalmente em bovinos leiteiros, associada à condição alimentar precária, o útero gravídico força o abomaso à frente interferindo na sua motilidade fisiológica, podendo resultar em uma obstrução parcial (Whitlock 1999). 
A compactação primária do abomaso ocorreu associada à compactação de omaso e/ou rúmen em 35,71\% dos casos (5/14), sendo complicada pelo avançado estado de gestação em $28,57 \%$ dos casos (4/11). Outras enfermidades como a indigestão vagal, compactação de omaso e esteatose hepática são comumente associadas à compactação do abomaso (Borges et al. 2007). Entre outros fatores, a retículoperitonite traumática e a peritonite associada com úlceras abomasais perfurantes são as causas mais comum de compactação de abomaso em bovinos nos Estados Unidos (Fubini \& Divers 2008), enquanto a compactação de abomaso de origem dietética é a forma mais comum em bovinos no Canadá, seguida pela retículoperitonite traumática (Ashcroft 1983).

As alterações hematológicas e do fibrinogênio plasmático consistiram de leucocitose por neutrofilia e hiperfibrinogenemia (Quadro 3) sugestivos de um processo inflamatório agudo (Cole et al. 1997, Morris \& Johnston 2006), no local da obstrução ou devido a possível comprometimento da parede do abomaso. Tais alterações hematológicas são consideradas comuns em alguns tipos de distúrbios obstrutivos, como na obstrução intestinal por fitobezoários (Afonso et al. 2008), enquanto em bovinos com estenose funcional posterior (indigestão vagal do tipo III), um aumento na contagem leucocitária e fibrinogênio plasmático foram observadas em apenas $20 \%$ e $50 \%$ dos casos, respectivamente (Braun et al. 1990).

As amostras de fluido ruminal analisadas apresentaram colorações variadas (Quadro 4). Estes achados são explicados pela grande variedade de alimentos na dieta dos animais (Dirksen et al. 1993). O odor apresentou-se aromático (9/12) e alterado (3/12), entretanto todos os animais apresentavam comprometimento da flora e fauna ruminal, fato evidenciado através da prova de redução do azul de metileno e a acentuada diminuição da atividade dos protozoários, respectivamente. Tais achados são justificados pela estase ruminal, que foi mais pronunciada em casos com evolução clínica mais prolongada. Acredita-se que a variação de consistência do fluído ruminal e valores de $\mathrm{pH}$ observados são decorrentes da anorexia e conseqüente pouca dinâmica digestiva que ocorreu na maioria dos casos analisados. A elevação do teor de cloretos no fluido ruminal se deve ao refluxo do conteúdo abomasal rico em ácido clorídrico para os proventrículos em função do comprometimento de fluxo da ingesta provocando um decréscimo nos valores séricos deste elemento, podendo ainda acarretar um quadro sistêmico de alcalose hipoclorêmica e hipocalêmica (Braun et al. 1990, Taguchi 1995, Dirksen 2005, Guard 2006, Radostitis et al. 2007, Fubini \& Divers 2008).

A associação dos achados clínicos com os resultados dos exames hematológicos, análise do fluido ruminal e dosagem do teor de cloretos permitiram o diagnóstico de distúrbio gastrintestinal obstrutivo e a laparotomia exploratória tanto pelo flanco esquerdo ou direito confirmaram o diagnóstico da enfermidade (Braun et al. 1990, Simkins \& Nagele 1997, Wittek et al. 2005, Borges et al. 2007).
O índice de sobrevivência obtido no tratamento clínico alcançou 50\% (4/8). A literatura cita resposta satisfatória ao tratamento instituído dependendo da severidade e cronicidade dos casos (Saint Jean \& Anderson 1999). Entretanto, o presente trabalho demonstra que mesmo animais com evolução clínica de poucos dias podem não responder a terapia clínica (Casos 2 e 7) ou cirúrgica (Casos 12 e 14) estando o prognóstico associado ao grau de compactação do abomaso e demais pré-estômagos (omaso e rúmen), sendo ainda mais reservado nos casos de gestação avançada. Os dois animais submetidos à laparotomia pelo flanco direito (Casos 4 e 6) apresentavam grau de compactação severo e não responderam à terapia clínica. Wittek et al. (2005) obtiveram $50 \%$ de sobrevivência utilizando a laparotomia pelo flanco direito associada à massagem do abomaso e aplicação de 3-4L de óleo mineral por via oral durante 1 a 5 dias, enquanto índices elevados como $83,3 \%$ podem ser alcançados com o uso constante de soluções poliônicas e glicosadas por via endovenosa (Braun et al. 1990). Trent (2004) ressalta que muitas vezes o tratamento clínico é considerado a única opção no manejo de casos múltiplos em nível de rebanho. $O$ índice de sobrevivência obtido foi superior ao relatado por Mitchell (1991) e Borges et al. (2007) que não obtiveram sucesso em nenhum dos casos em que foi tentado o tratamento conservativo e similar aos resultados de Simkins \& Nagele (1997).

O tratamento cirúrgico obteve índice de sobrevivência de 50\%. Simkins \& Nagele (1997) e Borges et al. (2007) não obtiveram êxito em nenhum dos animais tratados cirurgicamente com a mesma técnica, entretanto as substâncias lubrificantes utilizadas por via oral consistiram de parafina líquida e sementes de linhaça cozidas $(500 \mathrm{~g}$ em $10 \mathrm{~L}$ de água), respectivamente. Opções cirúrgicas foram comentadas por Trent (2004) que sugere que a laparotomia pelo flanco esquerdo seguida de rumenotomia deve ser associada, após 12-24 horas, a abomasotomia por abordagem paracostal direita inferior ou celiotomia paramediana direita, com resultado mais favorável em bezerros, e se não houver comprometimento da parede do abomaso. Entretanto, Guard (2006) ressalta que a intervenção cirúrgica através da abomasotomia não tem obtido êxito na restauração das funções do órgão. A rumenotomia com instalação de tubo nasogástrico inserido até o abomaso via orifício retículo-omasal através da incisão cirúrgica do rúmen é muito empregada, sendo possível a administração de laxantes e emulsificantes (Baker 1979, Saint Jean \& Anderson 1999), como foi realizado na conduta terapêutica dos animais neste estudo.

Reitera-se a importância do exame clínico minucioso a fim de identificar os sinais clínicos compatíveis com a compactação do abomaso associados, quando possível, a exames complementares, como o exame hematológico e análise do fluido ruminal, que permitem o diagnóstico de um distúrbio gastrintestinal obstrutivo. A técnica de laparotomia exploratória pelo flanco esquerdo ou direito permite o diagnóstico definitivo de inúmeras doenças digestivas em bovi- 
nos (Ducharme \& Fubini 2004), dentre elas a compactação de abomaso. As condutas clínica e cirúrgica citadas permanecem como opções viáveis para o tratamento das compactações leves e severas, entretanto o prognóstico é considerado reservado em todas as condições quando há a compactação do órgão, principalmente quando associado à gestação avançada, e a prevenção ainda é a melhor alternativa a ser adotada. Ainda pode-se concluir que o suco de mandacaru é uma opção barata e acessível como substância laxativa no tratamento de bovinos com compactação de abomaso, principalmente na região Nordeste, onde tal cactácea é abundante.

Agradecimentos.- Ao Prof. Dr. José Renato Junqueira Borges da Faculdade de Agronomia e Medicina Veterinária, Universidade de Brasília, por gentilmente ter revisado o manuscrito.

\section{REFERÊNCIAS}

Afonso J.A.B. \& Borges J.R.J. 2007. Compactação de rúmen, p.319322. In: Riet-Correa F., Schild A.L., Lemos R.A.A. \& Borges J.R.J. (Eds), Doenças de Ruminantes e Eqüídeos. Vol.2. Gráfica e Editora Palotti, Santa Maria.

Afonso J.A.B., Pereira A.L.L., Vieira A.C., Mendonça C.L., Costa N.A. \& Souza M.I. 2008. Alterações clínicas e laboratoriais na obstrução gastrintestinal por fitobezoários em bovinos. Revta Bras. Saúde Prod. Anim. 9(1):91-102.

Alves A.A. 1999. Digestibilidade e nutrientes digestíveis totais de camas de frango para ruminantes. Revta. Bras. Zootec. 28(5):1037-1041.

Andrade D.K.B., Ferreira M.A., Véras A.S.C., Wanderley W.L., Silva L.E., Carvalho F.F.R, Alves K.S. \& Melo W.S. 2002. Digestibilidade e absorção aparentes em vacas da raça Holandesa alimentadas com palma forrageira (Opuntia ficus-indica Mill) em substituição à silagem de sorgo (Sorghum bicolor (L.) Moench). Revta Bras. Zootec. 31(5): 2088-2097.

Ashcroft R.A. 1983. Abomasal impaction of cattle in Saskatchewan. Can. Vet. J. 24:375-380.

Baker J.S. 1979. Abomasal impaction and related obstruction of the forestomachs in cattle. J. Am. Vet. Med. Assoc. 175:1250-1253.

Blikslager A.T., Bristol D.G. \& Hunt E.L. 1993. Abomasal impaction in cattle. Compendium 15(11):1571-1575.

Borges J.R.J., Cunha P.H.J., Moscardini A.R.C., Franco G.L. \& Silva L.A.F. 2007. Compactação de abomaso em bovinos leiteiros: descrição de cinco casos. Ciência Anim. Bras. 8(4):859-864.

Braun U., Steiner A. \& Kaegi B. 1990. Clinical, haematological and biochemical findings and the results of treatment in cattle with acute functional pyloric stenosis. Vet. Rec. 3:107-110.

CEASA-PE. 2007. Programa Leite de Pernambuco, Fome Zero. Folheto, Perfil dos Lacticínios, Centro de Abastecimento Alimentar de Pernambuco, Recife. 55p.

Cebra C.K., Cebra M.L. \& Garry F.B. 1996. Gravel obstruction in the abomasum or duodenum of two cows. J. Am. Vet. Med. Assoc. 209 (7):1294-1296.

Cole D.J., Roussel A.J. \& Whitney H.S. 1997. Interpreting a bovine CBC: Evaluating the leukon and acute phase proteins. Vet. Med. 92:470478.

Coutinho L.T., Afonso J.A.B., Costa N.A., Mendonça C.L., Souza M.I., Pires Júnior J.B. \& Simão L.C.V. 2002. Aspectos clínicos e laboratoriais da dilatação do abomaso à direita em conseqüência da obstrução do piloro. Revta Bras. Med. Vet. 24(4):151-155.

Desrochers A. \& Saint Jean G. 1995. Cecal impaction in a cow. Can. Vet. J. 36:430-431.
Dirksen G. 2005. Enfermidades del abomaso, p.430-467. In: Dirksen G., Gründer H.-D. \& Stöber M. (Eds), Medicina Interna y Cirugía del Bovino. Vol.1. 4를 ed. Intermédica, Buenos Aires.

Dirksen G., Gründer H.-D. \& Stöber M. 1993. Rosenberger, Exame Clínico dos Bovinos. $3^{\mathrm{a}}$ ed. Guanabara Koogan, Rio de Janeiro. 419p.

Ducharme N.G. \& Fubini S.L. 2004. Surgery of the ruminant forestomach compartments, p.184-196. In: Fubini S.L. \& Ducharme N.G. (Eds), Farm Animal Surgery. W.B. Saunders, St Louis.

Fubini S. \& Divers T.J. 2008. Non infectious diseases of the gastrointestinal tract, p.130-199. In: Divers T.J. \& Peek S.M. (Eds), Rebhun's Diseases of Dairy Cattle. $2^{\text {nd }}$ ed. Saunders Elsevier, St Louis.

Guard C. 2006. Impactação abomasal, p.763-765. In: Smith B.P. (Ed.), Tratado de Medicina Interna de Grandes Animais. $3^{\text {a }}$ edição. Manole, São Paulo.

Hoffsis G.F. \& McGuirk S.M. 1993. Abomasal impactions in cattle, p.732733. In: Howard J.L. \& Smith R.A. (Eds), Current Veterinary Therapy: Food animal practice Vol.3. W.B. Saunders, Philadelphia.

Jain N.C. 1993. Essentials of Veterinary Hematology. Lea and Febinger, Philadelphia. 417p.

Kelton D.F. \& Fubini S.L. 1989. Pyloric obstruction after toggle pin fixation of left displaced abomasum in a cow. J. Am. Vet. Med. Assoc. 194:677678.

Kramer J.W. 2000. Normal hematology of cattle, sheep and goats, p.1075-1084. In: Feldman B.F., Zinkl J.G. \& Jain N.C. (Eds), Schalm's Veterinary Hematology. $5^{\text {th }}$ ed. Lippincott Williams and Wilkins, Philadelphia.

Melendez P., Krueger T., Benzaquen M. \& Risco C. 2007. An outbreak of sand impaction in postpartum dairy cows. Can. Vet. J. 48:10671070.

Mitchell K. 1991. Dietary abomasal impaction in a herd of dairy replacement heifers. J. Am. Vet. Med. Assoc. 198(8):1408-1409.

Morris D.D. \& Jonston J.K. 2006. Alterações nas proteínas do sangue, p.427-433. In: Smith B.P. (Ed.), Tratado de Medicina Interna de Grandes Animais. $3^{\underline{a}}$ ed. Manole, São Paulo.

Moscardini A.R.C. \& Borges J.R.J. 2007. Compactação de abomaso, p.352-355. In: Riet-Correa F., Schild A.L., Lemos R.A.A. \& Borges J.R.J. (Eds), Doenças de Ruminantes e Eqüídeos. Vol.2. Gráfica e Editora Palotti, Santa Maria.

Purohit N.R., Choudhary R.J. \& Choudan D.S. 1987. Abomasal impaction in a cow. Mod. Vet. Pract. 68 (5):308.

Radostitis O.M., Gay C.C., Hinchcliff K.W. \& Constable P.D. 2007. Veterinary Medicine: A textbook of the diseases of cattle, horses, sheep, pigs and goats. $10^{\text {th }}$ ed. W.B. Saunders, Edinburgh. 2156p.

Saint Jean G. \& Anderson D. 1999. Abomasal impactions in cattle, p.532533. In: Howard J.L. \& Smith R.A. (Eds), Current Veterinary Therapy: Food animal practice. Vol.4. W.B. Saunders, Philadelphia.

Simkins K.M. \& Nagele M.J. 1997. Omasal and abomasal impaction in beef suckler cows. Vet. Rec. 141:466-468.

Taguchi K. 1995. Relationship between degree of dehydration and serum electrolytes and acid-base status in cows with various abomasal disorders. J. Vet. Med. Sci. 57(2):257-260.

Trent A.M. 1990. Surgery of the bovine abomasum. Vet. Clin. North Am., Food Anim. Pract. 6:399-448.

Trent A.M. 2004. Surgery of the abomasum, p. 196-240. In: Fubini S.L. \& Ducharme N.G. (Eds), Farm Animal Surgery. W.B. Saunders, St Louis.

Wittek T., Constable P.D. \& Morin D.E. 2005. Abomasal impaction in Holstein-Friesian cows: 80 cases (1980-2003). J. Am. Vet. Med. Assoc. 227(2): 287-291.

Whitlock R. 1999. Vagal indigestion, p.517-522. In: Howard J.L. \& Smith R.A. (Eds), Current Veterinary Therapy: Food animal practice. Vol.4. W.B. Saunders, Philadelphia. 